\title{
Synthesis, Spectroscopic and Thermodynamic Studies of Metal Complexes with Schiff Bases Derived from 2-[5-(Pyridin-2-Ylmethylene)-amino] 1,3,4-Oxadiazol-2-yl-Phenol
}

\author{
Naser Shaalan, Sahar S. Hassan and Abbas Ali Salih Al-Hamdani \\ Department of Chemistry, College of Science for Women, University of Baghdad, Baghdad-Iraq. \\ E-mail: ndsh1972@gmail.com.
}

\begin{abstract}
New metal complexes of the ligand 2-[5-(Pyridin-2-ylmethylene)-amino] 1,3,4-thiadiazol-2-ylphenol (L) with the metal ions $\mathrm{Co}(\mathrm{II}), \mathrm{Ni}(\mathrm{II}), \mathrm{Cu}(\mathrm{II})$ and $\mathrm{Zn}(\mathrm{II})$ were prepared in alcoholic medium. The Schiff base was condensed [2-pyridine carbxaldehyde] with [2-amino-5-(phenyl-1,3,4oxadiazole] in alcoholic medium. Two tetradentate Schiff bases ligand were used for complexation upon two metal ions of $\mathrm{Co}^{2+}, \mathrm{Ni}^{2+}, \mathrm{Cu}^{2+}$ and $\mathrm{Zn}^{2+}$ as dineucler formula $\mathrm{M}_{2} \mathrm{~L}_{2}$. The synthesized compound and their metal complexes were characterized by FTIR Spectroscopy, electronic spectroscopy, Elemental analysis, magnetic susceptidbility measurements, thermal analysis , ${ }^{1} \mathrm{H}-$ NMR spectra, and mass spectra. The activation thermodynamic parameters such as $\Delta \mathrm{E}^{*}, \Delta \mathrm{H}^{*}, \Delta \mathrm{S}^{*}$ and $\Delta \mathrm{G}^{*}$ were calculated from the TGA curve using Coats-Red fern method. From the measurements, structures of the complexes were proposed.
\end{abstract}

Keywords: Schiff base, Microwave synthesis, Thermodynamic Parameters.

\section{Introduction}

A large number of Schiff base compounds derived from aromatic amines and aromatic aldehydes have a wide range of applications in many fields like biological, inorganic and analytical chemistry [1]. Increasing physiological importance of nitrogen and oxygen donor organic compounds and active role played by coordination certain metal ions to them. Have interested use in synthesizing and studying structural aspects of metal complexes with some oxygen and nitrogen donor ligands [2].

Literature survey reveals that out of various isomers particularly 1,3,4-oxadiazole derivatives exhibit wide range of biological activities [3]. Also various route for the synthesis of 1,3,4-oxadiazole have been reported[4-6]. These activities are probably due to the presence of the $-\mathrm{N}=\mathrm{C}-\mathrm{O}$ group [7]. Pyridin; oxadiazol and its derivatives form an important class of organic compounds due to their structural chemistry and biological activities as analgesic, antipyretics and antiinflammatory [8]. In addition Pyridin can form a variety of Schiff bases are reported to be superior reagents in biological, clinical and analytical applications $[9,10]$. In continuation of our work on the metal complexes of Schiff bases, we report here the study of some new, $\mathrm{Co}(\mathrm{II}), \mathrm{Ni}$ (II), $\mathrm{Cu}$ (II) and $\mathrm{Zn}$ (II) complexes of Schiff bases derived from Pyridin and 2-amino-5-(2-hydroxy-phenyl-1,3,4-oxadiazole. Preparation and characterization of above metal ion complexes with this Schiff bases are reported here. Where, HL is a Schiff base of 2amino-5-(2-hydroxy-phenyl-1,3,4- oxadiazol with Pyridin Matel ion complexes with some oxygen and nitrogen donor ligands[11]. From the TGA curves recorded for the successive steps in the decomposition process of these ligand and complexes it was possible to determine the following characteristic thermal parameters for each reaction step: Initial point temperature of decomposition (Ti): the point at which TG curve starts dzviating from its base line. Final point temperature of decomposition (Tf): the point at which TG curve returns to its base line. Peak temperature, i.e. temperature of maximum rate of weight loss: the point obtained from the intersection of tangents to the peak of TG curve. Mass loss at the decomposition step (Dm): it is the amount of mass that extends from the point $\mathrm{Ti}$ up to the reaction end point $\mathrm{Tf}$ on the $\mathrm{TG}$ curve, i.e. the magnitude of the ordinate of a TG curve. The material released at each step of the decomposition is identified by attributing the mass loss (Dm) at a given step to the component of similar weight calculated from the molecular formula of the investigated complexes, comparing that with literatures of 
relevant compounds considering their temperature. This may assist identifying the mechanism of reaction in the decomposition steps taking place in the complexes under study. Activation energy (E) of the composition step: the integral method used is the Coats-Redfern equation [12]. for reaction order $n \neq 1$ or $n=2$, which when linearised for $a$ correctly chosen $n$ yields the activation energy from the slop;

$$
\begin{aligned}
& \log \left[\frac{1-(1-\alpha)^{1-\mathrm{n}}}{\mathrm{T}^{2}(1-\mathrm{n})}\right]=\log \frac{\mathrm{ZR}}{\mathrm{qE}}\left[1-\frac{2 \mathrm{RT}}{\mathrm{E}}\right]-\frac{\mathrm{E}}{2.303 \mathrm{RT}} \ldots \ldots \mathrm{n} \neq 1 \\
& \log \left[\frac{-\log \cdot(1-\alpha) \cdot}{T^{2}}\right]=\log \cdot\left[\frac{A R}{\beta E}\left(1-\frac{2 R T}{E}\right]-\frac{E}{2.303 R T} \ldots \ldots \mathrm{n}=1\right.
\end{aligned}
$$

$\Delta S^{*}=2.303 R\left[\log \left(A h / K \quad T_{\max }\right)\right], \quad \Delta H^{*}=E-$ $\mathrm{RT}_{\max }, \Delta \mathrm{G}^{*}=\Delta \mathrm{H}^{*}-\mathrm{T}_{\max } \Delta \mathrm{S}^{*}$ where: $\alpha=$ fraction of weight loss, $\mathrm{T}=$ temperature $\left({ }^{\circ} \mathrm{K}\right), \mathrm{n}=$ order of reaction, $\mathrm{A}$ or $\mathrm{Z}=$ preexponential factor, $\mathrm{R}=$ molar gas constant, $\mathrm{E}=$ activation energy and $\mathrm{q}=$ heating rate . Order of reaction (n): it is the one for which a plot of the Coats-Redfern expression gives the best straight line among various trial values of $\mathrm{n}$ that are examined relative to that estimated by the Horovitz-Metzger method [13].

\section{Experimental}

All chemical used were of reagent grade (supplied by either sigma Aldrich or fluka) and used as supplied. The FTIR spectra in the range (4000-400) $\mathrm{cm}^{-1}$ cut were recorded as $\mathrm{KBr}$ disc on FTIR.4200 Jasco Spectrophotometer. The UV-Visible spectra were measured in ethanol using Shimadzu UV-Vis. 160 A-Ultra-violet Spectrophotometer in the range (200-1000) $\mathrm{nm}$. Magnetic Susceptibility measurement for complexes were obtained at room temperature using (Magnetic Susceptibility Balance) Jhonson Mattey Catalytic Systems Division. Gallencamp M.F.B600.010 F melting point apparatus were used to measure the melting point of all the prepared compounds. Elemental microanalysis was carried out using Elemental Analyzer Model 5500 Carlo-Erba Instruments (Italy) microwave monelax.

\section{1)- Synthesis of [2-amino-5-(2-hydroxy- phenyl-1,3,4-oxiadiazole] [14] [A]}

A-Synthesis Semicarbazone: Semicarbazide Hydrochloride $(0.1 \mathrm{~mol})$ and sodium acetate $(0.2 \mathrm{~mol})$ were added and dissolved in $15-20 \mathrm{~mL}$ of distilled water placed in flat-bottomed flask. In a separate beaker containing required Salicylaldehyde $(0.1 \mathrm{~mol})$ was dissolved in absolute alcohol. This ethanolic aromatic aldehyde solution was added slowly to the solution of semicarbazide hydrochloride. The precipitate, were separated, was filtered, dried and recrystallised from $95 \%$ hot ethanol.

B-Semicarbazone $(0.1 \mathrm{~mol})$ and sodium acetate $(0.2 \mathrm{~mol})$ was dissolved in $300-400 \mathrm{~mL}$ of glacial acetic acid with continuous stirring. Bromine ( $7 \mathrm{~mL}$ in $50 \mathrm{~mL}$ of GAA) was added slowly to it. Solution was stirred for an hour and then poured on crushed ice. The resulting solid was separated,dried and recrystallised from hot ethanol (95\%) yield, elemental analysis is show in Table (1).

\section{2)-2-[5-(Pyridin-2-ylmethylene)-amino] 1,3,4-oxadiazol-2-yl-phenol [L]}

Method (1): A mixture of equimolar amounts $(0.05 \mathrm{~mol})$ of appropriate [2-pyridine carbxaldehyde] and the [2-amino-5-(2hydroxy-phenyl-1,3,4-oxiadiazole], in absolute ethanol (25 ml) with (3) drops of glacial acetic acid was refluxed (4) hours. The reaction mixture was then allowed to cool at room temperature, and the precipitate was filtered, dried, and recrystallized from mixture (methanol and ethanol) (1:1) to give yellow powder.

Method (2): A mixture of equimolar amounts $(0.05 \mathrm{~mol})$ of appropriate [2-pyridine carbxaldehyde] and the (2-amino-5(2-hydroxy-phenyl-1,3,4-oxadiazole), were ground with a mortar, mixed, dried and subjected to microwave irradiation $240 \mathrm{~W}$ for (15) minutes, after completion the reaction mixture was cooled to room temperature the solid obtained was recrystallized twice from mixture (methanol and ethanol) (1:1) to give yellow powder, yield, elemental analysis is show in Table (1). 


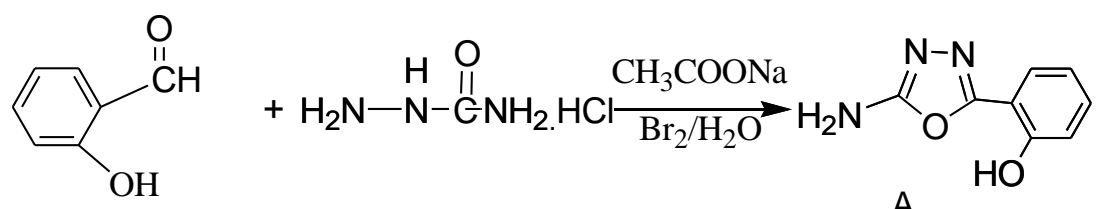

A<smiles>Nc1nnc(C2=CC=[C+]C=C2O)o1</smiles>

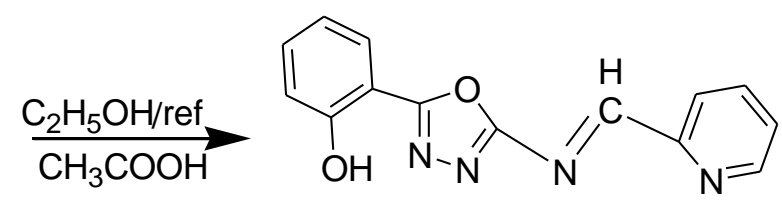

L

Scheme (1)

\section{Preparation of complexes}

Method (1): An ethanol solution of the metal salte of $\mathrm{Co}(\mathrm{II}), \mathrm{Ni}$ (II), $\mathrm{Cu}$ (II) or $\mathrm{Zn}$ (II) were added to an ethanolic solution of (L) in 1:1 (metal : ligand) molar ratios. Stirring for 2 hours with heating $70{ }^{\circ} \mathrm{C}$, crystalline colored precipitates formed after cooling at room temperature, the resulting solids were filtered off, washed with distilled water, dried and recrystallized from ethanol and dried at $50{ }^{\circ} \mathrm{C}$.

Method (2): An ethanol solution of the metal salte of $\mathrm{Co}(\mathrm{II}), \mathrm{Ni}$ (II), $\mathrm{Cu}$ (II) or $\mathrm{Zn}$ (II)were added to an ethanolic solution of (L) in 1:1 (metal : ligand) molar ratios. And put in ultrasonic bath heating $65{ }^{\circ} \mathrm{C}$. After 50 mints crystalline colored precipitates formed after cooling at room temperature, the resulting solids were filtered off, washed with distilled water, dried and recrystallized from ethanol and dried at $50{ }^{\circ} \mathrm{C}$. yield, C.H.N.S analysis are shown in Table (1).

\section{Result and Discussion}

The synthetic procedure of Schiff base ligand are presented in Scheme (1). The reactions of divalent transition metal ions viz., $\mathrm{Co}(\mathrm{II}), \quad \mathrm{Ni}(\mathrm{II}), \quad \mathrm{Cu}(\mathrm{II})$ and $\mathrm{Zn}(\mathrm{II})$. The composition of the complexes formed in solution has been established by mole ratio and job methods. In both cases the results reveals $(2: 2)$ metal to ligand ratio yielded the corresponding metal chelates. Shows the decomposition point, color and electronic absorption bands for ligand and complexes in Table $(1,2)$. The bands are classified into three distinct groups: The intermolecular transitions appear in the UV region, charge transfer from ligand to metal, and d-d transitions appear in the UV-Visible region. 1-[2-amino-5-(2-hydroxy-phenyl-1,3,4oxiadiazole] [A]

The reaction of Semicarbazide Hydrochloride with Salicylaldehyde in presence of sodium acetate/ $\mathrm{Br}_{2}$ afforded 2amino-5-phenyl-1,3,4-oxiadiazole[14]. The structural assignment of the product was based on it's melting point and spectral (FT-IR and UV/Vis.) data in Table $(1,2)$. The FT-IR spectrum of compound (A) exhibited significant two band in the range (3402$3213) \mathrm{cm}^{-1}$ which could be attributed to asymmetric and symmetric stretching vibrations of $\mathrm{NH}_{2}$ group. band in the (3428) $\mathrm{cm}^{-1}$ stretching vibrations of $(\mathrm{OH})$. Besides this, band at about (1475-1423 $\left.\mathrm{cm}^{-1}\right)$ due to cyclic $(\mathrm{C}=\mathrm{N})$ stretching is also observed. Bands at $\left(1518 \mathrm{~cm}^{-1}\right)$ and $\left(1484 \mathrm{~cm}^{-1}\right)$ are due to the $(\mathrm{N}-\mathrm{H})$ bending and $(\mathrm{C}-\mathrm{N})$ stretching vibrations, respectively $[15,16]$.

\section{2) 2-[5-(Pyridin-2-ylmethylene)-amino] 1,3,4-oxadiazol-2-yl-phenol [L]}

The FT-IR spectra show the disappearance of the two absorption bands due to $\left(-\mathrm{NH}_{2}\right)$ stretching of amino oxiadiazole [L] showed all the suggested bonds for olefinic $(\mathrm{C}-\mathrm{H}),(\mathrm{C}=\mathrm{C})$ aromatic, endocyclic $(\mathrm{C}=\mathrm{N})$ and exocyclic imine group. Stretching vibrations in addition to out of plane bending of substituted aromatic ring. All the prepared compounds (Schiff bases) exhibited the stretching band near the region $\left(1419-1478 \mathrm{~cm}^{-1}\right)$ this due to $(=\mathrm{N}-\mathrm{N}=\mathrm{C}-)$ cyclic group; $3426 \mathrm{~cm}-1$ (v OH Stretching), a band at $1415-1469 \mathrm{~cm}^{-1}$ attributed to (vibration of Pyridin ring), $1595 \mathrm{~cm}^{-1}$ (v C=N Stretching of amine), $1229 \mathrm{~cm}^{-1}, \quad 1468 \mathrm{~cm}^{-1}$ (Characteristic bands of oxadiazole ring). All the spectral data for other compounds are listed in Table (3). 
${ }^{1} \mathrm{H}-\mathrm{NMR}$ spectrum of compounds [L] Fig.(1), shows the following characteristic chemical shift, (CDCL3- $\mathrm{d}_{6}$ ) ppm. The four aromatic ring protons $(\delta 7.285-8.696)(\mathrm{s}, 4 \mathrm{H}$, $\mathrm{Ar})$, and four Pyridin ring appeared protons at $(\delta 6.144-7.18) \mathrm{ppm}$, the signal at $(\delta 8.885)$ attributed to $(\mathrm{N}=\mathrm{C}-\mathrm{H})$ proton (azomethine), the signal at $\delta=10.874(\mathrm{~s}, 1 \mathrm{H}, \mathrm{OH}), \delta 1.572$ (Solvent organic).

The positive ion mass spectral analysis of (L) observe at $\mathrm{m} / \mathrm{z}$ 266.4. (M+1) Fig.(2), confirms the theoretical molecular weight i.e. 266. 25.
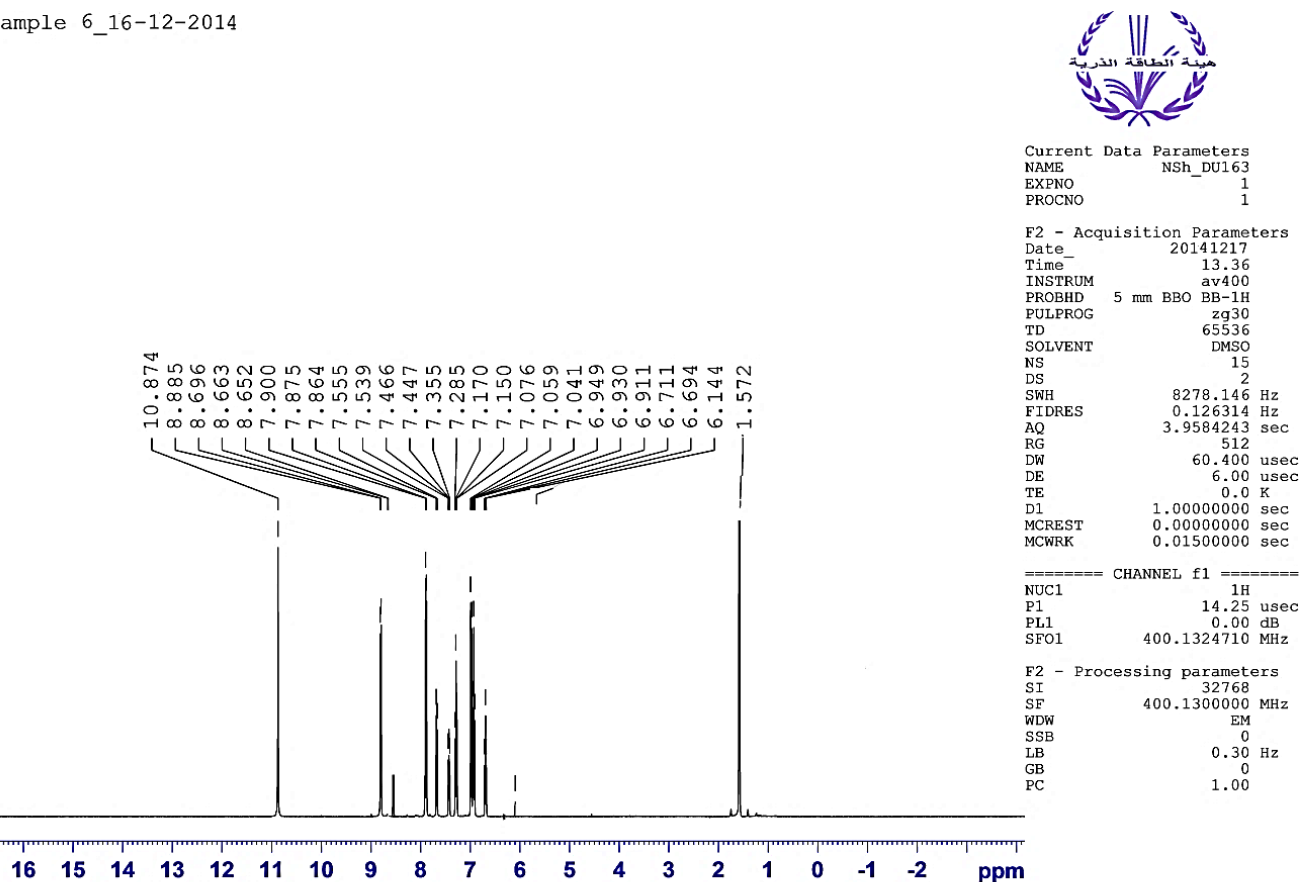

(⿸广⿱⺊口)

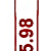

Fig.(1): ${ }^{1}$ H-NMR For the ligand (L).

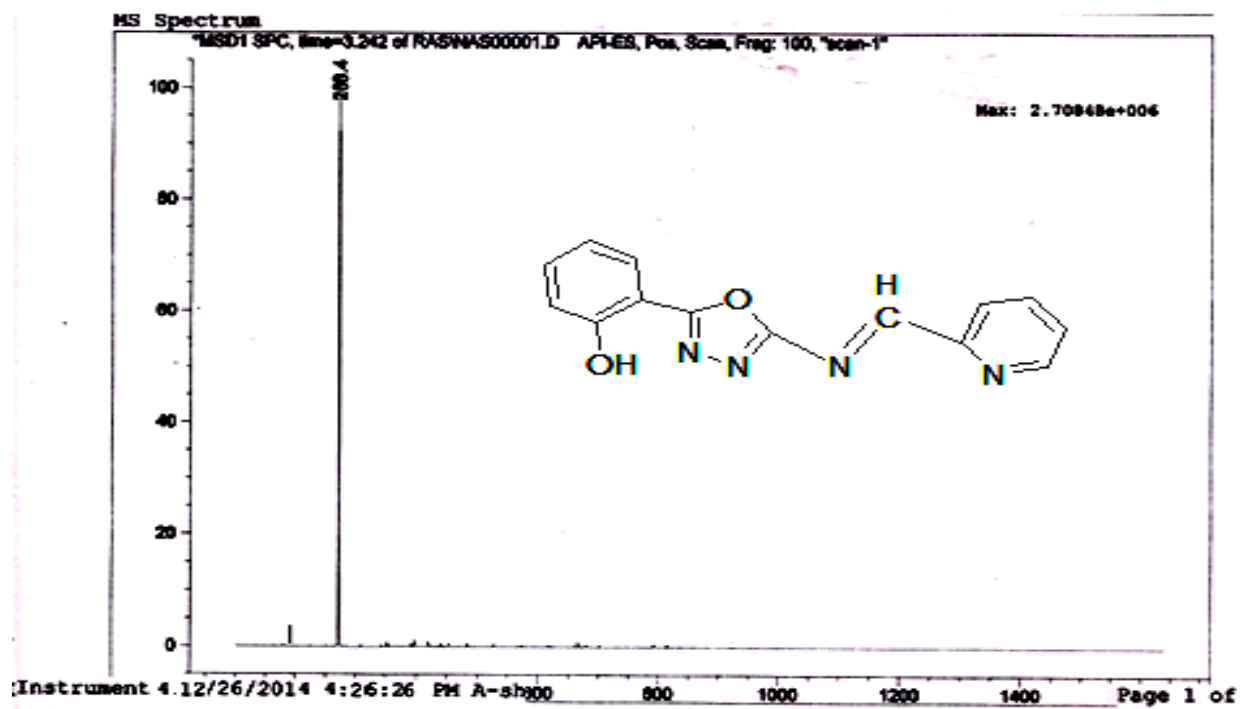

Fig.(2): LC-MS for ligand (L). 
Table (1)

The characterization data of the prepared compounds/ Found (calcd).

\begin{tabular}{|c|c|c|c|c|c|c|c|}
\hline Compound Formula, & Yield & $C$ & $H$ & $N$ & $O$ & $\mathrm{Cl}$ & $M$ \\
\hline $\begin{array}{c}\mathrm{A} \\
\mathrm{C}_{8} \mathrm{H}_{7} \mathrm{~N}_{3} \mathrm{O}_{2} \\
\end{array}$ & $70 \%$ & $\begin{array}{c}54.60 \\
(54.24) \\
\end{array}$ & $\begin{array}{c}3.82 \\
(3.98) \\
\end{array}$ & $\begin{array}{l}23.39 \\
(23.72) \\
\end{array}$ & $\begin{array}{c}18.19 \\
(18.06) \\
\end{array}$ & --- & -- \\
\hline $\begin{array}{c}\mathrm{L} \\
\mathrm{C}_{14} \mathrm{H}_{10} \mathrm{~N}_{4} \mathrm{O}_{2} \\
\end{array}$ & $73 \%$ & $\begin{array}{c}62.74 \\
(63.15) \\
\end{array}$ & & $\begin{array}{l}21.25 \\
(21.04) \\
\end{array}$ & $\begin{array}{c}12.10 \\
(12.02) \\
\end{array}$ & --- & -- \\
\hline$\left[\mathrm{Co}_{2}(\mathrm{~L})_{2}\left(\mathrm{H}_{2} \mathrm{O}\right)_{4}\right] \mathrm{Cl}_{2}$ & $81 \%$ & $\begin{array}{c}41.94 \\
(42.50) \\
\end{array}$ & $\begin{array}{c}3.37 \\
(3.31)\end{array}$ & $\begin{array}{c}14.81 \\
(14.16)\end{array}$ & $\begin{array}{c}16.02 \\
(16.17)\end{array}$ & $\begin{array}{c}9.13 \\
(8.96)\end{array}$ & $\begin{array}{l}14.73 \\
(14.89)\end{array}$ \\
\hline$\left[\mathrm{Ni}_{2}(\mathrm{~L})_{2}\left(\mathrm{H}_{2} \mathrm{O}\right)_{4}\right] \mathrm{Cl}_{2}$ & $76 \%$ & $\begin{array}{c}42.06 \\
(42.52) \\
\end{array}$ & $\begin{array}{c}3.22 \\
(3.31) \\
\end{array}$ & $\begin{array}{c}14.49 \\
(14.17) \\
\end{array}$ & $\begin{array}{c}16.33 \\
(16.18) \\
\end{array}$ & $\begin{array}{c}9.18 \\
(8.97) \\
\end{array}$ & $\begin{array}{c}14.71 \\
(14.84) \\
\end{array}$ \\
\hline$\left[\mathrm{Cu}_{2}(\mathrm{~L})_{2}\left(\mathrm{H}_{2} \mathrm{O}\right)_{4}\right] \mathrm{Cl}_{2}$ & $75 \%$ & $\begin{array}{c}41.56 \\
(42.01) \\
\end{array}$ & $\begin{array}{c}3.24 \\
(3.27) \\
\end{array}$ & $\begin{array}{c}14.31 \\
(14.00) \\
\end{array}$ & $\begin{array}{c}15.69 \\
(15.99) \\
\end{array}$ & $\begin{array}{c}9.03 \\
(8.86) \\
\end{array}$ & $\begin{array}{c}16.17 \\
(15.88) \\
\end{array}$ \\
\hline$\left[\mathrm{Zn}_{2}(\mathrm{~L})_{2}\left(\mathrm{H}_{2} \mathrm{O}\right)_{4}\right] \mathrm{Cl}_{2}$ & $68 \%$ & $\begin{array}{c}41.28 \\
(41.82) \\
\end{array}$ & $\begin{array}{c}3.17 \\
(3.26) \\
\end{array}$ & $\begin{array}{c}14.10 \\
(13.93) \\
\end{array}$ & $\begin{array}{c}16.03 \\
(15.92) \\
\end{array}$ & $\begin{array}{c}9.01 \\
(8.82) \\
\end{array}$ & $\begin{array}{c}16.41 \\
(16.26)\end{array}$ \\
\hline
\end{tabular}

Table (2)

Some physical data electronic spectra for ligand and complexes in DMF.

\begin{tabular}{|c|c|c|c|c|c|c|}
\hline Symbol & $\begin{array}{l}\text { Dec. } \\
\text { Point } \\
{ }^{0} \mathrm{C}\end{array}$ & $\begin{array}{l}\text { Conductivity } \\
\mathrm{ohm}^{-1} \mathrm{~cm}^{2} \mathrm{~mol}^{-1}\end{array}$ & $\begin{array}{c}\text { Magnetic } \\
\text { Moment } \\
\text { (B.M) }\end{array}$ & Color & $\begin{array}{c}\text { Absorptio } \\
\text { n Bands } \\
(n m)\end{array}$ & $\begin{array}{l}\text { Assigned } \\
\text { Transition }\end{array}$ \\
\hline \multirow{2}{*}{ A } & \multirow{2}{*}{244} & \multirow{2}{*}{-} & \multirow{2}{*}{-} & \multirow{2}{*}{$\begin{array}{l}\text { White- } \\
\text { yellow }\end{array}$} & 215 & $\pi \rightarrow \pi^{*}$ \\
\hline & & & & & 285 & $\mathrm{n} \rightarrow \pi^{*}$ \\
\hline \multirow{2}{*}{$\mathrm{L}$} & \multirow{2}{*}{$285 d$} & \multirow{2}{*}{--} & \multirow{2}{*}{-} & \multirow{2}{*}{$\begin{array}{l}\text { White- } \\
\text { yellow }\end{array}$} & 225 & $\pi \rightarrow \pi^{*}$ \\
\hline & & & & & 395 & $\mathrm{n} \rightarrow \pi^{*}$ \\
\hline \multirow{3}{*}{$\begin{array}{c}{\left[\mathrm{Co}_{2}(\mathrm{~L})_{2}\left(\mathrm{H}_{2} \mathrm{O}\right)_{4}\right]} \\
\mathrm{Cl}_{2}\end{array}$} & \multirow{3}{*}{$300 d$} & \multirow{3}{*}{138} & \multirow{3}{*}{4.75} & \multirow{3}{*}{ Pale-Red } & 770 & ${ }^{4} \mathrm{~T}_{1} \mathrm{~g} \rightarrow{ }^{4} \mathrm{~A}_{2} \mathrm{~g}$ \\
\hline & & & & & 555 & ${ }^{4} \mathrm{~T}_{1} \mathrm{~g}^{(\mathrm{F})} \rightarrow{ }^{4} \mathrm{t}_{1} \mathrm{~g}^{(\mathrm{p})}$ \\
\hline & & & & & 350 & Charge Transfer \\
\hline \multirow{5}{*}[\mathrm{Ni}_{2}(\mathrm{L})_{2}(\mathrm{H}_{2}\mathrm{O})_{4}]{$\mathrm{Cl}_{2}$} & \multirow{5}{*}{$300 d$} & \multirow{5}{*}{161} & \multirow{5}{*}{3.19} & \multirow{5}{*}{ Pale green } & 225 & $\pi \rightarrow \pi^{*}$ \\
\hline & & & & & 300 & $\mathrm{n} \rightarrow \pi^{*}$ \\
\hline & & & & & 375 & Charge Transfer \\
\hline & & & & & 650 & ${ }^{3} \mathrm{~A}_{2} \mathrm{~g} \rightarrow{ }^{3} \mathrm{t}_{1} \mathrm{~g}^{(\mathrm{p})}$ \\
\hline & & & & & 950 & ${ }^{3} \mathrm{~A}_{2} \mathrm{~g} \rightarrow{ }^{3} \mathrm{t}_{1} \mathrm{~g}^{(\mathrm{F})}$ \\
\hline \multirow{4}{*}[\mathrm{Cu}_{2}(\mathrm{L})_{2}(\mathrm{H}_{2}\mathrm{O})_{4}]{$\mathrm{Cl}_{2}$} & \multirow{4}{*}{$300 d$} & \multirow{4}{*}{147} & \multirow{4}{*}{1.92} & \multirow{4}{*}{$\begin{array}{l}\text { Light } \\
\text { Brawn }\end{array}$} & 225 & $\pi \rightarrow \pi^{*}$ \\
\hline & & & & & 295 & $\mathrm{n} \rightarrow \pi^{*}$ \\
\hline & & & & & 370 & Charge Transfer \\
\hline & & & & & $\begin{array}{c}430,615, \\
635 \\
\end{array}$ & ${ }^{2} \mathrm{~B}_{1} \mathrm{~g} \rightarrow{ }^{2} \mathrm{~B}_{2} \mathrm{~g}$ \\
\hline$\left[\mathrm{Zn}_{2}(\mathrm{~L})_{2}\left(\mathrm{H}_{2} \mathrm{O}\right)_{4}\right] \mathrm{Cl}_{2}$ & $300 d$ & 159 & Dia & $\begin{array}{l}\text { White- } \\
\text { yellow }\end{array}$ & 325 & Charge Transfer \\
\hline
\end{tabular}

\section{Infrared spectral analysis of metal} complexes

The infrared spectra of the ligands shows (vO-H) (weakly H-bonded) at $3421 \mathrm{~cm}^{-1}$. The absence of this band in all the metal complexes indicates the removal of proton of hydroxyl group of benzene ring during the chelation. The sharp intense band at $1595 \mathrm{~cm}^{-1}$ in the ligands can be assigned to $v \mathrm{C}=\mathrm{N}$ (azomethine). A shift $\left(\Delta v=8-22 \mathrm{~cm}^{-1}\right)$ in $v \mathrm{C}=\mathrm{N}$ (azomethine) is observed upon coordination indicating that the nitrogen of azomethine group is involved in coordination. All the complexes show broad band in the region (3295-3378) $\mathrm{cm}^{-1}$ which may be assigned to $(v \mathrm{O}-\mathrm{H})$ of coordinated water[17] . To account for the octahedral stereochemistry of the metal complexes, the coordination of two water molecules is expected.

The bands at $541 \mathrm{~cm}^{-1}$ in $\mathrm{Co}$ (II) complexes, $591 \mathrm{~cm}^{-1}$ in $\mathrm{Ni}$ (II) complexe, $590 \mathrm{~cm}^{-1}$ in $\mathrm{Cu}$ (II) complexe and $575 \mathrm{~cm}^{-1}$ in $\mathrm{Zn}$ (II) 
complexe may be due to metal-nitrogen stretching vibration[18,19]. All the metal complexe involved in coordination in the free ligand, the band at (1478-1419) $\mathrm{cm}^{-1}$ is assigned to the stretching of $(\mathrm{C}-\mathrm{N}=\mathrm{N}-\mathrm{C})$ oxadizole ring. On complexation, this band was shifted to a high frequency region. This shift is probably due to the lowering of bond order of the carbon-nitrogen bond resulted from complexation of the metal to the ligand through nitrogen in $(\mathrm{vC}=\mathrm{N})$ compared to its respective ligands. This suggests that the nitrogen atom of the ring has not participated in the chelation. However, in water containing chelates, this band is observed as a broad with structure this may be due to coupling of the bending mode of coordinated [20].

Table (3)

Infrared data of Ligand and its metal complexes $\left(\mathrm{cm}^{-1}\right)$.

\begin{tabular}{|c|c|c|c|c|c|c|c|}
\hline Symbol & $v(C=N)$ & $\begin{array}{l}\text { Pyridin } \\
\text { ring }\end{array}$ & $v(C-N=N-C)$ & $v(M-O)$ & $v(\mathrm{H} 2 \mathrm{O})$ & $v(O-H)$ & $v(M-N)$ \\
\hline $\mathrm{L}$ & $1595(\mathrm{~s})$ & 1415 & $1478-1419$ & - & - & 3395 & - \\
\hline$[\mathrm{Co} 2(\mathrm{~L}) 2(\mathrm{H} 2 \mathrm{O}) 4] \mathrm{Cl} 2$ & $1610(\mathrm{~s})$ & 1427 & $1488-1431$ & $483 w$ & 3275 & - & $541 \mathrm{w}$ \\
\hline$[\mathrm{Ni} 2(\mathrm{~L}) 2(\mathrm{H} 2 \mathrm{O}) 4] \mathrm{Cl} 2$ & $1617(\mathrm{~s})$ & 1427 & 1491-1433 & $534 \mathrm{w}$ & 3281 & - & $591 \mathrm{w}$ \\
\hline [Cu2 (L)2(H2O)4] Cl2 & $1603(\mathrm{~s})$ & 1431 & 1489-1430 & $448 \mathrm{w}$ & 3241 & 3378 & $590 \mathrm{w}$ \\
\hline [Zn2 (L)2(H2O)4] Cl2 & $1611(\mathrm{~s})$ & 1434 & 1479-1433 & $483 w$ & 3255 & 3295 & $575 \mathrm{w}$ \\
\hline
\end{tabular}

\section{Thermal analysis}

To understand thermal decomposition process, Schiff bass and its metal complexes were examined by thermo gravimetric analysis in the temperature range of $35-700{ }^{\circ} \mathrm{C}$ Fig.(3). The obtained thermo analytical results from TGA curves for all these compounds are given in Table (4). The decomposition was completed at $693{ }^{\circ} \mathrm{C}$ for all the complexes. The data from the thermo gravimetric analyses indicated that the decomposition of the complexes and the ligand proceeds in (two or three) steps. The final decomposition products were metal oxide mixture formed above $598{ }^{\circ} \mathrm{C}$ for the metal [21]. Plot $\log \mathrm{K}$ against $1 / \mathrm{T}{ }^{\circ} \mathrm{K}$ and determine the slope of the straight line relation, calculate of the values of the kinetic and thermodynamic factors (n order of reaction, $\mathrm{Z}$ (pre-exponential factor), $\left(\Delta \mathrm{S}^{*}\right)$ entropy, $\left(\Delta \mathrm{H}^{*}\right)$ enthalpy, $\left(\Delta \mathrm{G}^{*}\right)$ Gibbs free energy) from Table (4) thermal analysis (TG) curves by way Coates Radefrn Coats- Redfern.

We find that the positive values for $\left(\Delta \mathrm{G}^{*}\right)$ indicate that interactions is automatic (nonspontaneous) in the case of transformation. The negative values for $(\Delta S *)$ indicate that ligand have a more structured installation (more ordered structure) of the reactants and the reactions are slow more than the natural or formal. As for the positive ( $\Delta \mathrm{H}^{*}$ values) indicate that interactions endothermic). Negative values indicate that the interactions conducive to heat and small values of the coefficient of (Z) show that the fast dissociation reactions ligand while large positive values and when the case can be classified as slow-moving reactions. 


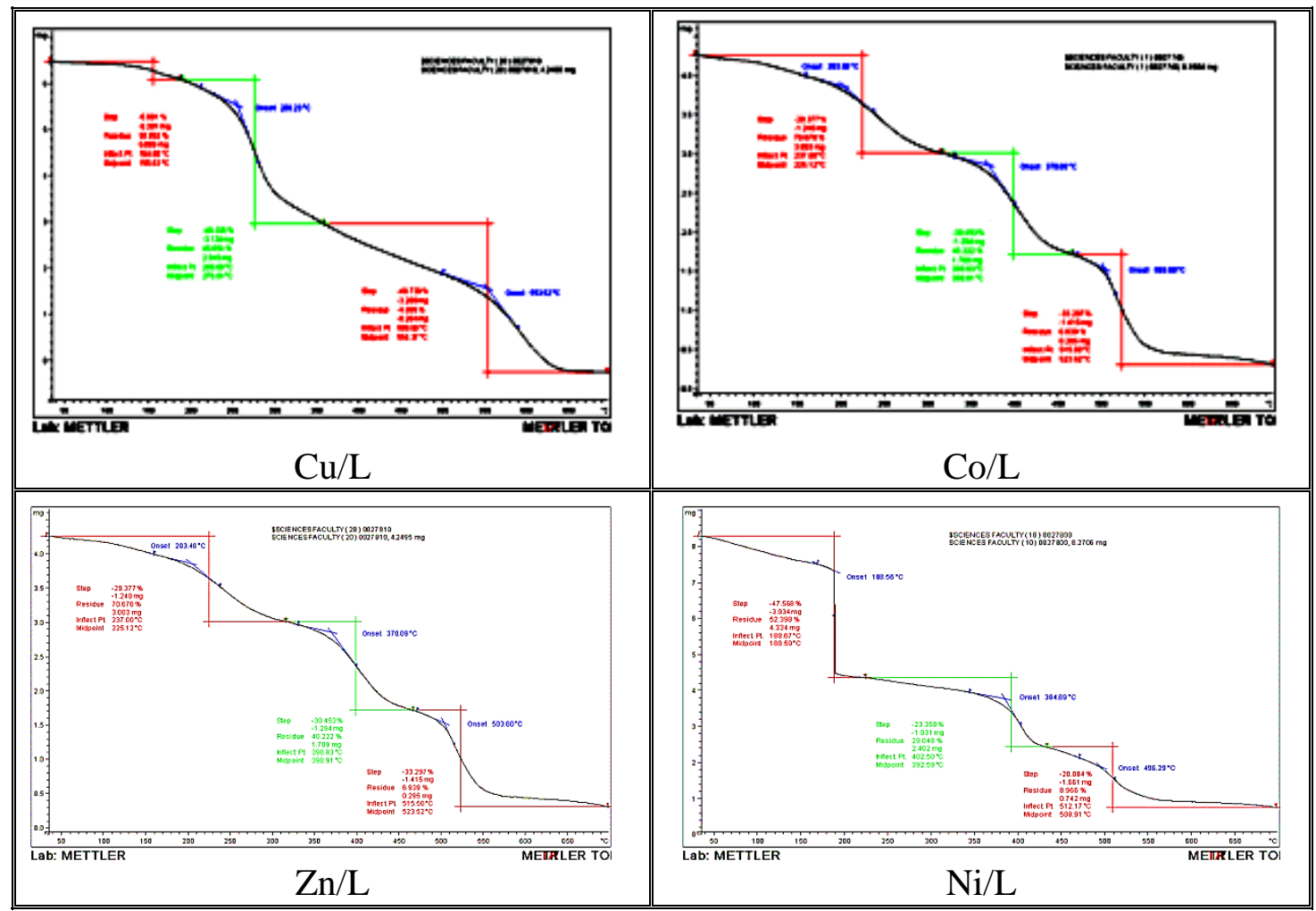

Fig.(3): Thermal analysis for complexes.

Table (4)

Thermodynamic parameters of the ligand and metal complexes.

\begin{tabular}{|c|c|c|c|c|c|c|c|c|c|}
\hline $\begin{array}{c}\text { Sample } \\
\text { (step) }\end{array}$ & $\begin{array}{c}\text { T.range } \\
{ }^{\circ} \mathrm{C} \\
\end{array}$ & $N$ & $R^{2}$ & $\boldsymbol{T}_{\max }{ }^{o} \mathrm{~K}$ & $\begin{array}{c}E a \\
\text { K.J mol }{ }^{-1}\end{array}$ & $\begin{array}{c}\Delta \mathrm{H}^{*} \\
\mathrm{KJ} \mathrm{mol}^{-1} \\
\end{array}$ & $\begin{array}{c}\mathrm{ZSec}^{-1} \\
x 10^{5}\end{array}$ & $\begin{array}{c}\Delta S^{*} \\
\mathrm{~J} \mathrm{~mol}^{-1} \mathrm{~K}^{-1} \\
\end{array}$ & $\begin{array}{c}\Delta G^{*} \\
K J \mathrm{~mol}^{-1}\end{array}$ \\
\hline $\mathrm{L}_{1}(1)$ & $37-380$ & 1 & 0.99 & 545.50 & 70.25 & 65.53 & 16.66 & -230.2 & 190.45 \\
\hline $\begin{array}{l}\mathrm{L}_{1}(2) \\
\end{array}$ & 380-700 & 0.9 & 0.99 & 840.50 & -11.23 & -18.11 & $4.3 \times 10^{-5}$ & -375.3 & 279.21 \\
\hline $\mathrm{Co}(1)$ & $37-370$ & 0.9 & 0.99 & 4476.4 & 31.57 & 27.62 & 7.25 & -291.78 & 165.65 \\
\hline $\mathrm{Co}(2)$ & $370-470$ & 0.9 & 1 & 644.21 & -7.92 & -12.17 & 5.6 & -355.84 & 214.09 \\
\hline $\mathrm{Co}(3)$ & 4470-700 & 0.9 & 0.99 & 766.6 & -6.65 & -13.282 & 6.35 & -352.37 & 260.62 \\
\hline $\mathrm{Ni}(1)$ & $37-140$ & 0.9 & 0.99 & 384 & 20.45 & 16.92 & 0.00451 & -312.457 & 136.17 \\
\hline $\mathrm{Ni}(2)$ & 140-390 & 0.9 & 0.99 & 507 & 36.5 & 32.2919 & 0.017 & $\begin{array}{l}-287.19 \\
\end{array}$ & 175.8 \\
\hline $\mathrm{Ni(3)}$ & 390-700 & 0.9 & 0.99 & 775.12 & -11.19 & $\begin{array}{l}-17.62 \\
\end{array}$ & 35.4 & -259.25 & 259.25 \\
\hline $\mathrm{Cu}(1)$ & $\begin{array}{l}37-170 \\
\end{array}$ & 0.9 & 0.99 & 4423 & 123.9 & 446.49 & 7.68 & -222.79 & 135.39 \\
\hline $\mathrm{Cu}(2)$ & 170-400 & 0.9 & 0.99 & 2554 & 54.24 & 121.04 & 0.5357 & -101.22 & 170.56 \\
\hline $\mathrm{Cu}(3)$ & 400-700 & 0.9 & 1 & 726.35 & 12.66 & -5.734 & 4.91 & -359.81 & 311.7 \\
\hline $\mathrm{Zn}(1)$ & $37-160$ & 1 & 0.99 & 525 & 8.26 & 3.95 & $4.3 \times 10^{-6}$ & -352.4 & 187.67 \\
\hline Zn (2) & 160-430 & 0.9 & 0.99 & 678 & $\begin{array}{c}-10.22 \\
\end{array}$ & -15.85 & $3.9 \times 10^{-6}$ & -355.3 & 225.23 \\
\hline Zn (3) & $430-700$ & 0.9 & 0.99 & 810 & -10.86 & -17.69 & $3.4 \times 10^{-6}$ & -357.9 & 279.75 \\
\hline
\end{tabular}

\section{Molar Ratio Method}

In this investigation, the concentration of the metal ions were maintained constant and the ligands concentrations were varied [21], so a series of metal-ligand aqueous ethanolic solutions were prepared with different $[\mathrm{L}] /[\mathrm{M}]$ ratios. The absorptions of these solutions were measured using UV spectrophotometer at $\lambda$ max of the expected complex $\mathrm{M}_{2} \mathrm{~L}_{2}$.
Absorbance versus $[\mathrm{L}] /[\mathrm{M}]$ curves were drawn for all complexes.

From the FTIR Spectroscopy, electronic spectroscopy, Elemental analysis, magnetic susceptibility measurements, thermal analysis suggest the following structure. 


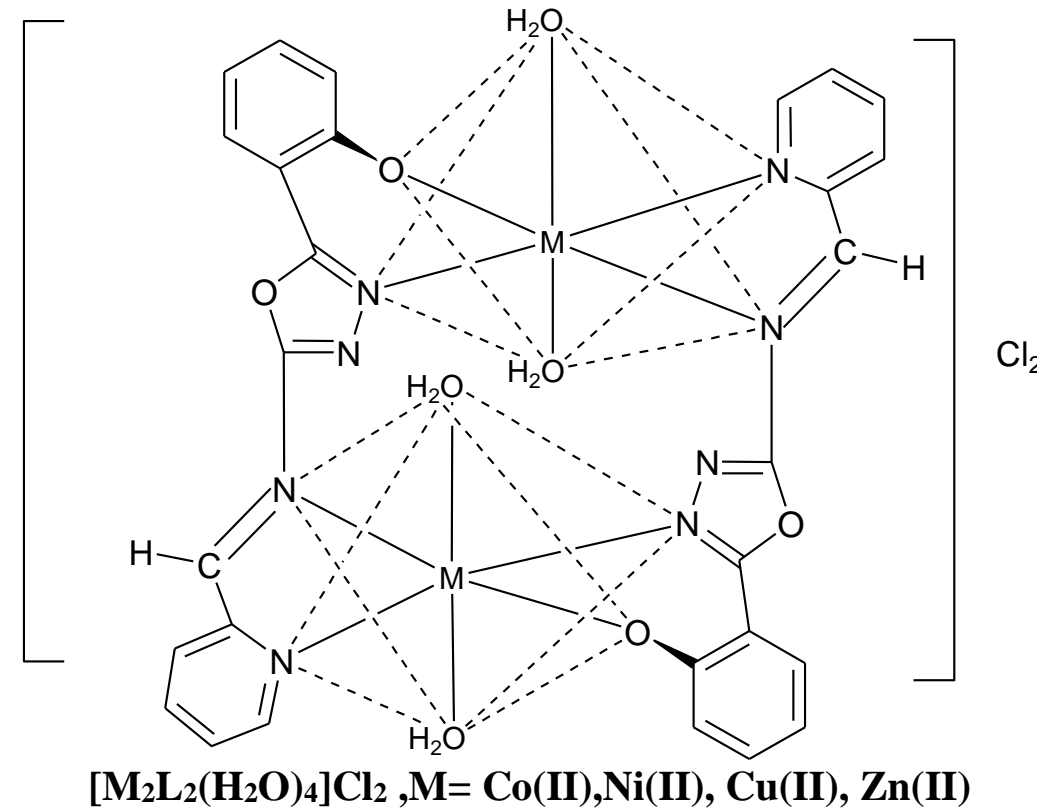

\section{References}

[1] Fauzi A, Bahron H, Kassim K, Zain M "Synthesis ,characterization and neurotoxic effect of Schiff's bases Ligands their complexes" Malaysian Journal of Analytical Sciences, 15 (1):. 93-100, 2011.

[2] H Zainab, Yousif E, Ahmed A and Altaie A "Synthesis and characterization of Schiff's bases of sulfamethoxazole" Springer J. Organic and Medicinal Chemistry Letters, 4:1, 2014.

[3] R Rakesh, Y Prabhakar, S Shirodkar., "Oxadiazole: A biologically important heterocycle" Der Pharma Chemica, 1 (1): 130-140, 2009.

[4] Waston B., Tierney J. and Lidstrom P. "Microwave dielectric heating in modern organic synthesis and drug discovery" Drug Discovery Today, 6:pp. 373-380, 2002.

[5] M. Fantini, V. Zuliani, M. A. Spotti, M. Rivara "Microwave Assisted Efficient Synthesis of Imidazole-Based Privileged Structures" Journal of Combinatorial Chemistry, 12 (1): 181-185, 2010.

[6] Khan K.M., Rani M. and Haider S.M., Lett. Org. Chem., 1: 151-154, 2004.

[7] Yousif E. Ameer A.A and Sabbah A.M, "Complexes of 2-Amino -5- (ppropoxyphenyl)-1,3,4-oxadiazole with Some Metal Ions". journal of Al-Nahrain University, 2:.65-69, 2004.

[8] Abbiati G, Arcadi A, Attanasi O A, De Crescentini L and Rossi E, "Synthesis of functionalised pyrazolones and imidazolines /imidazoles through divergent cyclisation reactions" Tetrahedron, 57: 2031-2038, 2001.

[9] Yang Z. Y, Yang R D, Li F S and Yu K B. “(Z)-4-\{1-[(2-Hydroxyethyl)amino]ethylidene \}-3-methyl-1-phenyl-1H-pyrazol5(4H)-one" Polyhedron, 19: 2599-2564, 2001.

[10] Joshi K.T., Dabhi H.R., Pancholi A.M. and Rana A.K., "Ligand field parameters of $\mathrm{Cu}$ (II), $\mathrm{Ni}$ (II) and $\mathrm{Co}$ (II) chelates with some 4-substituted-1-phenyl-3-methyl-2pyrazolin-5-ones", Orient. J.Chem., 12 (3): 287-290, 1996.

[11] Emad, Y., Hadeel A., Farah M. Synthesis and characterization of some metal ions with 2-amino acetate benzothiazol. Journal of applied sciences research, 6(7): PP. 879-882, 2010.

[12] Coats, A.W. and Redfern, J. P., "Kinetic parameters from thermogravimetric". Nature, 201:pp. 68, 1964.

[13] Horovitz, H. H. and Metzger, G., "Analysis of thermogravimetric traces as an approach to determine the mechanism of dissociation of copper (II)- $\alpha$-aryl azo acetoacetyl aminopyridine chelates". Thermochimica Acta, 159: 43-54,1963

[14] Johnsoa, A and Wilcox; (1969) Lab. Exp. Org. Chem. The Macmillan Company, Collier Macmillan Limited, London, 1969. 
[15] Chudgar,N.K; Shan,S.N and Vorat, R.A; (1989) "Mesogenic Semicarbazones and Amino Oxadiazoles"; Mol. Cryst. Liq. Cryst; 172, 51-56, 1989.

[16] Sliverstien R.; Bassler G.; Morrill T. Spectrometric Identification of Organic Compounds. $7^{\text {th }}$ addition, John-Wiley, New York, 2005.

[17] Nakamoto K, Infrared spectra of Inorganic and coordination Compounds, John Willey, New York, 1963.

[18] Adans D M. "Metal-Ligand and related Vibration", Edward Arnold, London, 33: 310-321, 1967.

[19] Rahman S M F, Ahmad J and Haq M. M, “Tris-(salicylaldehyde)-complexes"J Inorg Nucl Chem, Journal of scientific Research., 4(4): 229-234, 2009.

[20] Sahoo, K. K. Das, P. K. and Nayak, S. C. "Synthesis and Characterization of Some Cobalt (III) 35, 1011-1021, 1973.

[21] Sarika, R. Y. Amit, R. Y. Gaurav, B. P. and Anand, S. A. "Synthesis and characterization of transition metal complexes with $\mathrm{N}$, O-chelating Hydrazone Schiff base ligand", American-Eurasian Complexes Containing Heterocyclic Nitrogen Donor Ligands", Chem Pap ., 57 (2): 91-96, 2003.

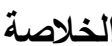

[Mرت

حيث باستخدام الليكند =L-(Pyridin-2-ylmethylene)-2-2-2 amino] 1,3,4-thiadiazol-2-yl-phenol

حضرت من تفاعل 5-(2-هيدروكسي فنيل)4,3,1اوكسادايازول مع 2- بردين كربوكسي الدهايد في الكحول النقي. شخصت المعقدات المحضرة بتقنية أطياف الآشعة الثردية تحت الحمراء وأطباف الإليكترونية وطيف الكتلة و النووي

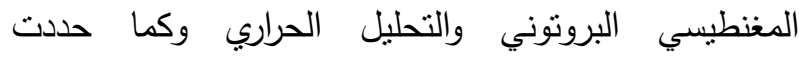
البارامترات الثرموديناميكية معادلة Coats-Red fern من أطياف التحلل الحراري ألوزني باعين

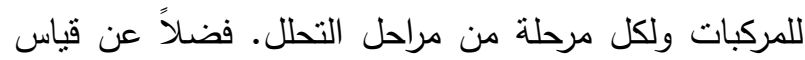

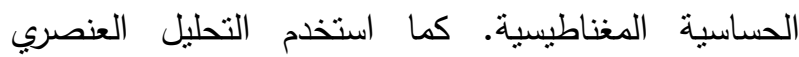

للمساعدة في عملية التنخيص، حيث تم اقتراح شكل البنية الأساسية للمعقدات. تم قياس النسب المولية المتغيرة في المحلول فأعطت نتائج مطابقة مع تلك التي تم الحصول عليها في الحالة الصلبه ومن نتائج الاطياف تم اقتراح شكل

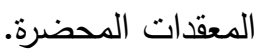

